\title{
Caracterização tecnológica de um calcário dolomítico in natura, calcinado e sulfatado como meio dessulfurante
}

\section{(Technological characterization of in nature, calcined and sulfated dolomitic limestone as means to dessulfuration)}

\author{
F. de Souza, S. R. Bragança \\ Laboratório de Materiais Cerâmicos, Universidade Federal do Rio Grande do Sul, Av. Osvaldo Aranha, 99, \\ Porto Alegre, RS 90035-190
}

\begin{abstract}
Resumo
Calcários são muito utilizados na captura das emissões gasosas sulfurosas emitidas durante a queima do carvão na geração de energia, por meio de sua injeção em caldeiras e fornalhas. A caracterização técnica deste material torna-se necessária à correta seleção e utilização de uma rocha calcária. Neste trabalho, foi realizada a análise técnica e microestrutural dessa matéria-prima, incluindo-se a caracterização dos parâmetros físico-químicos, texturais e microestruturais do calcário in natura, calcinado e sulfatado. Um calcário dolomítico foi avaliado quanto às propriedades físico-químicas, distribuição de tamanhos de partículas, área específica, volume de poros e análise em microscópio eletrônico de varredura. Por apresentar origem metamórfica, o calcário apresentou-se compacto e pouco poroso, porém após a calcinação a textura muda drasticamente, com a diminuição da densidade, aumento da superfície reativa e desenvolvimento de porosidade aberta. Estes são parâmetros fundamentais a um bom sorvente de óxido de enxofre. A fratura de partículas é gerada pela pressão interna durante a conversão dos carbonatos em óxido de cálcio e liberação do $\mathrm{CO}_{2}$ durante a calcinação. O óxido de cálcio nascente reage com óxido de enxofre, formando uma camada compacta de sulfato de cálcio, a qual reduz a área específica pelo bloqueio dos poros, causando o aumento de granulometria média e relativa, na etapa de sulfatação. A caracterização tecnológica realizada mostrou aspectos relevantes quanto à microestrutura dos calcários calcinados e sulfatados. A pressão gerada pelo $\mathrm{CO}_{2}$ durante a sulfatação, resultado da calcinação incompleta do calcário, é capaz de romper a fina camada de $\mathrm{CaSO}_{4}$, deixando poros arredondados.
\end{abstract}

Palavras-chave: calcário, caracterização tecnológica, calcinação, sulfatação.

\begin{abstract}
Limestones are widely used to capture sulfur gas emissions emitted during the burning of coal in power generation through its injection in boilers and furnaces. The technical characterization of this material becomes necessary to correct selection and use of a limestone rock. In this work, the technical and microstructural analysis of this raw material, including the characterization of the limestone in nature, calcined, and sulfated was performed. A limestone was evaluated in respect to physicochemical properties, particle size distribution, surface area, pore volume and SEM analysis. The metamorphic origin of the limestone explains its compact and little porous appearance, but after calcination the texture changes dramatically, with decreasing density, increased reactive surface and development of open porosity. These are key parameters for a good sulfur oxide sorbent. The fracture of particles is generated by the internal pressure during conversion of the carbonate into calcium oxide and release of $\mathrm{CO}_{2}$ during calcination. The calcium oxide reacts with sulfur oxide forming a compact layer of calcium sulphate, which reduces the specific area by blocking the pores, causing an increase in average and relative particle size during sulfation stage. The technological characterization performed revealed important aspects about the microstructure of calcined and sulfated limestone. The pressure generated by $\mathrm{CO}_{2}$ during sulfation, resulting from incomplete calcination of the limestone, is capable of breaking the thin layer of $\mathrm{CaSO}_{4}$ leaving rounded pores therein.
\end{abstract}

Keywords: limestone, technological characterization, calcination, sulfation.

\section{INTRODUÇ̃̃O}

Os sorventes baseados em cálcio (calcários e dolomitas) são amplamente utilizados na remoção de compostos de enxofre (SOx) durante a geração de energia proveniente do carvão mineral. A abundância e o baixo custo tornam o calcário atraente para diversas aplicações. Porém, uma caracterização adequada desta matéria-prima se faz necessária para o entendimento das suas propriedades físico-químicas, texturais e microestruturais em diferentes etapas de reação. A composição de um calcário denota a porção de constituintes diferentes química ou fisicamente, porém, a similaridade entre as propriedades físicas dos minerais carbonatados resulta numa dificuldade na distinção entre eles $[1,2]$.

Com o objetivo de caracterizar os sorventes calcários, são utilizadas análises químicas como fluorescência de raios $\mathrm{X}$, e mineralógicas como a difração de raios $\mathrm{X}$, as quais 
são muito úteis na descrição dos minerais, especialmente quando combinado com os parâmetros de textura dos mesmos [2]. Parâmetros físicos como tamanho de partícula, área específica e volume de poros compreendem a textura do calcário e juntamente com técnicas de microscopia são utilizadas na análise da microestrutura desta matéria-prima.

$\mathrm{Na}$ calcinação, o calcário se decompõe para formar $\mathrm{CaO}$ e $\mathrm{CO}_{2}$ segundo a reação:

$$
\mathrm{CaCO}_{3(\mathrm{~s})} \rightarrow \mathrm{CaO}_{(\mathrm{s})}+\mathrm{CO}_{2(\mathrm{~g})}
$$

Neste processo, um calcário originalmente compacto e denso é transformado em um material poroso e mais reativo pela liberação do $\mathrm{CO}_{2}$ de sua estrutura interna $[3$, 4]. A perda dos componentes voláteis tende a aumentar a área específica do calcário à medida que os gases são liberados do seu interior no decorrer da reação [4-6]. Como resultado da calcinação, a porosidade do calcário aumenta em até $54 \%$, reduzindo o volume molar do mesmo em $45 \%$ do volume normal do adsorvente (o volume molar do $\mathrm{CaCO}_{3}$ é $36,9 \mathrm{~cm}^{3} / \mathrm{mol}$ enquanto o volume molar do $\mathrm{CaO}$ é $16,9 \mathrm{~cm}^{3} / \mathrm{mol}$ ) [5,7]. Com o aumento da temperatura durante a calcinação, pode ocorrer a sinterização e a decrepitação das partículas. Na sinterização, a elevação da temperatura pode provocar o amolecimento e aglomeração de algumas partículas contribuindo para o incremento da fração de grossos; já na decrepitação, a liberação dos gases $\left(\mathrm{CO}_{2}, \mathrm{H}_{2} \mathrm{O}\right.$, etc..) no interior da partícula, provoca o aumento da pressão interna, e como consequência ocorre a fragmentação dos grãos e enriquecimento das populações mais finas [8].

A sulfatação é uma importante reação gás-sólido de primeira ordem, onde o calcário reage com o $\mathrm{SO}_{2}$, formando uma nova fase sólida - a anidrita $\left(\mathrm{CaSO}_{4}\right)$ [9]. Na presença de $\mathrm{O}_{2}$ e acima de aproximadamente $700{ }^{\circ} \mathrm{C}$, o $\mathrm{CaSO}_{4}$ é o principal produto na sulfatação do calcário, e a reação global é assim representada [10]:

$$
\mathrm{CaCO}_{3(\mathrm{~s})}+\mathrm{SO}_{2(\mathrm{~g})}+1 / 2 \mathrm{O}_{2(\mathrm{~g})} \rightarrow \mathrm{CaSO}_{4(\mathrm{~s})}+\mathrm{CO}_{2(\mathrm{~g})}
$$

A sulfatação do $\mathrm{CaO}$ consiste na reação na superfície externa com difusão de $\mathrm{SO}_{2}$ através dos poros da partícula, e difusão em estado sólido através da camada de produto formado $\left(\mathrm{CaSO}_{4}\right)$ [7, 11]. A cinética de sulfatação depende, em larga medida, do tipo de calcário, ou seja, de sua origem geológica; e as diferenças de conversão são consequência da composição e morfologia do sorvente [12]. As impurezas como os sais de metais alcalinos não participam da sulfatação diretamente, porém podem ter alguma importância na continuidade da mesma, afetando a taxa de difusão ou transporte iônico, pois originam defeitos pontuais no retículo cristalino [13, 14]. Na sulfatação indireta, ocorre um bloqueio dos poros externos que rapidamente forma uma camada impenetrável de $\mathrm{CaSO}_{4}$. Isto leva a uma significante quantidade de partículas reagidas sob o mecanismo do núcleo não reagido [10]. Com a substancial recristalização que ocorre na calcinação e sulfatação, a textura do calcário sofre uma grande mudança [15]. A sulfatação ocorre em grande extensão entre 700 a $800{ }^{\circ} \mathrm{C}$, tornando a superfície rugosa e mudando a textura do $\mathrm{CaSO}_{4}$ e as propriedades microestruturais do $\mathrm{CaO}$ nascente também influenciam na sulfatação [7, 13]. Por este motivo, são necessários estudos acerca das propriedades dos sorventes calcários.

O objetivo deste trabalho foi realizar a caracterização tecnológica e microestrutural de um calcário in natura, calcinado e sulfatado, com base nas propriedades físicoquímicas, texturais e de microestrutura.

\section{MATERIAIS E MÉTODOS}

Neste estudo foi utilizado um calcário metamórfico, proveniente da região de Pantano Grande, RS, e um carvão mineral proveniente de Candiota, RS. O calcário, classificado como dolomítico, foi utilizado em granulometria média de $\sim 50 \mu \mathrm{m}$, medida por granulômetro a laser.

A caracterização química e mineralógica foi realizada por fluorescência de raios X (espectrômetro Shimadzu, XRF-1800) e difração de raios X (Philips X'Pert), respectivamente, e é apresentada na Tabela I e Fig. 1.

A calcinação do calcário foi feita em termobalança Mettler Toledo TG/SDTA 851e, em atmosfera de $\mathrm{O}_{2}$ com taxa de aquecimento $10{ }^{\circ} \mathrm{C} / \mathrm{min}$ até $1200{ }^{\circ} \mathrm{C}$, e em forno de resistência elétrica até $850{ }^{\circ} \mathrm{C}$ por $1 \mathrm{~h}$ com taxa de aquecimento de $2,5^{\circ} \mathrm{C} / \mathrm{min}$. Em forno, a calcinação por aquecimento gradual foi feita introduzindo a amostra no forno e esperando alcançar a temperatura desejada; porém, na calcinação por choque térmico, esperou-se o forno alcançar a temperatura desejada para então introduzir a amostra, onde permaneceu por $\sim 30 \mathrm{~min}$.

A sulfatação foi em forno a $850{ }^{\circ} \mathrm{C}$ por $1 \mathrm{~h}$, com taxa de $2,5{ }^{\circ} \mathrm{C} / \mathrm{min}$, e o cadinho com calcário calcinado foi acondicionado entre os cadinhos contendo carvão mineral, para garantir o contato com o $\mathrm{SO}_{2}$ durante a queima.

A microestrutura do calcário in natura, calcinado e sulfatado foi visualizada em microscópio eletrônico de varredura (Hitachi TM3000) com capacidade de ampliação de até 30.000 vezes, com feixes de 5 e $15 \mathrm{keV}$. As amostras foram colocadas sobre um suporte de alumínio

Tabela I - Composição química do calcário dolomítico (\%).

[Table I - Chemical composition of dolomitic limestone (\%).]

\begin{tabular}{ccccccccc}
\hline $\mathrm{CaO}$ & $\mathrm{MgO}$ & $\mathrm{SiO}_{2}$ & $\mathrm{Al}_{2} \mathrm{O}_{3}$ & $\mathrm{Fe}_{2} \mathrm{O}_{3}$ & $\mathrm{~K}_{2} \mathrm{O}$ & $\mathrm{TiO}_{2}$ & $\mathrm{P}_{2} \mathrm{O}_{5}$ & Perda ao Fogo \\
\hline 33,72 & 9,5 & 11,17 & 1,3 & 0,59 & 0,32 & 0,04 & 0,02 & 43,34 \\
\hline
\end{tabular}




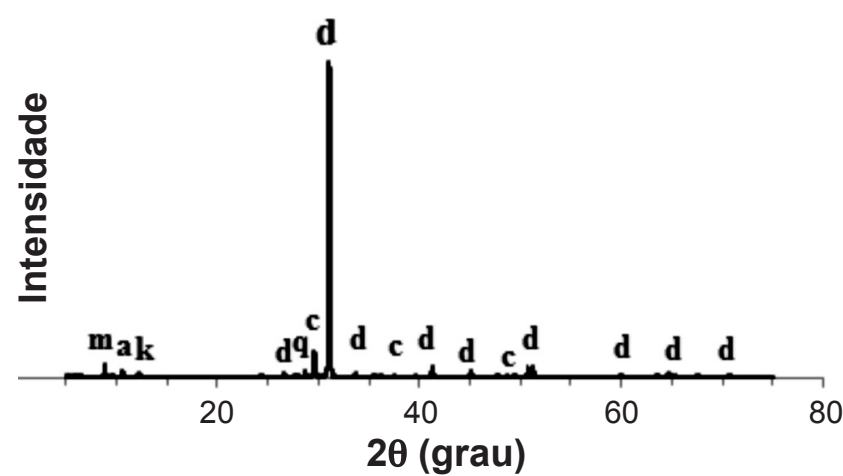

Figura 1: Difratograma de raios $\mathrm{X}$ do calcário dolomítico; a: argilomineral; c: calcita; d: dolomita; k: caolinita; m: muscovita; q: quartzo.

[Figure 1: XRD pattern of dolomitic limestone; a: clay mineral c: calcite d: dolomite $\mathrm{k}$ : kaolinite, m: muscovite q: quartz.]

previamente preparado com uma fita adesiva de carbono, e então visualizadas. Também foi utilizado um microscópio eletrônico de varredura JEOL JSM 6060, com voltagem de aceleração de 0,3 a $30 \mathrm{kV}$ e capacidade de ampliação de até 300.000 vezes. Nesse microscópio a visualização foi feita após metalização das partículas de calcário com ouro.

A área específica e o volume de poros foram determinados pelo método BET em analisador de área específica (Quantachrome Nova 1000), com nitrogênio como gás de adsorção. As amostras foram pré-tratadas em vácuo por $3 \mathrm{~h}$ a $300{ }^{\circ} \mathrm{C}$. Na análise granulométrica foi empregado um granulômetro a laser (Cilas 1180).

A densidade das amostras foi determinada em um multi picnômetro a gás hélio Quantachrome MVP-1.

\section{RESULTADOS E DISCUSSÃO}

\section{Caracterização do calcário in natura}

$\mathrm{Na}$ caracterização química, o calcário dolomítico apresentou como maiores impurezas sílica e magnésio (Tabela I). O magnésio em grande parte encontrase distribuído como dolomita quando se observa o difratograma de raios $X$ (Fig. 1). A sílica, além dos argilominerais, também está presente formando quartzo. A presença de quartzo é indesejável em sorventes calcários por representar a fração inerte. Outras impurezas, entre elas ferro, alumínio e sais de metais alcalinos ( $\mathrm{K}$ e $\mathrm{P}$ ) também fazem parte do calário dolomítico, porém em pequenas quantidades (Tabela I). Entre as fases principais no difratograma de raios $\mathrm{X}$ estão calcita e dolomita, mas picos de muscovita, caolinita e quartzo também apareceram (Fig. 1).

O calcário dolomítico caracteriza-se pela estrutura compacta quando observado em microscópio eletrônico de varredura, por tratar-se de um calcário metamórfico (Fig. 2). Porém alguns poros e superfície desigual formada por degraus também foram observados. Já foi mostrado que um calcário dolomítico apresenta estrutura menos compacta do que um calcário calcítico [5].
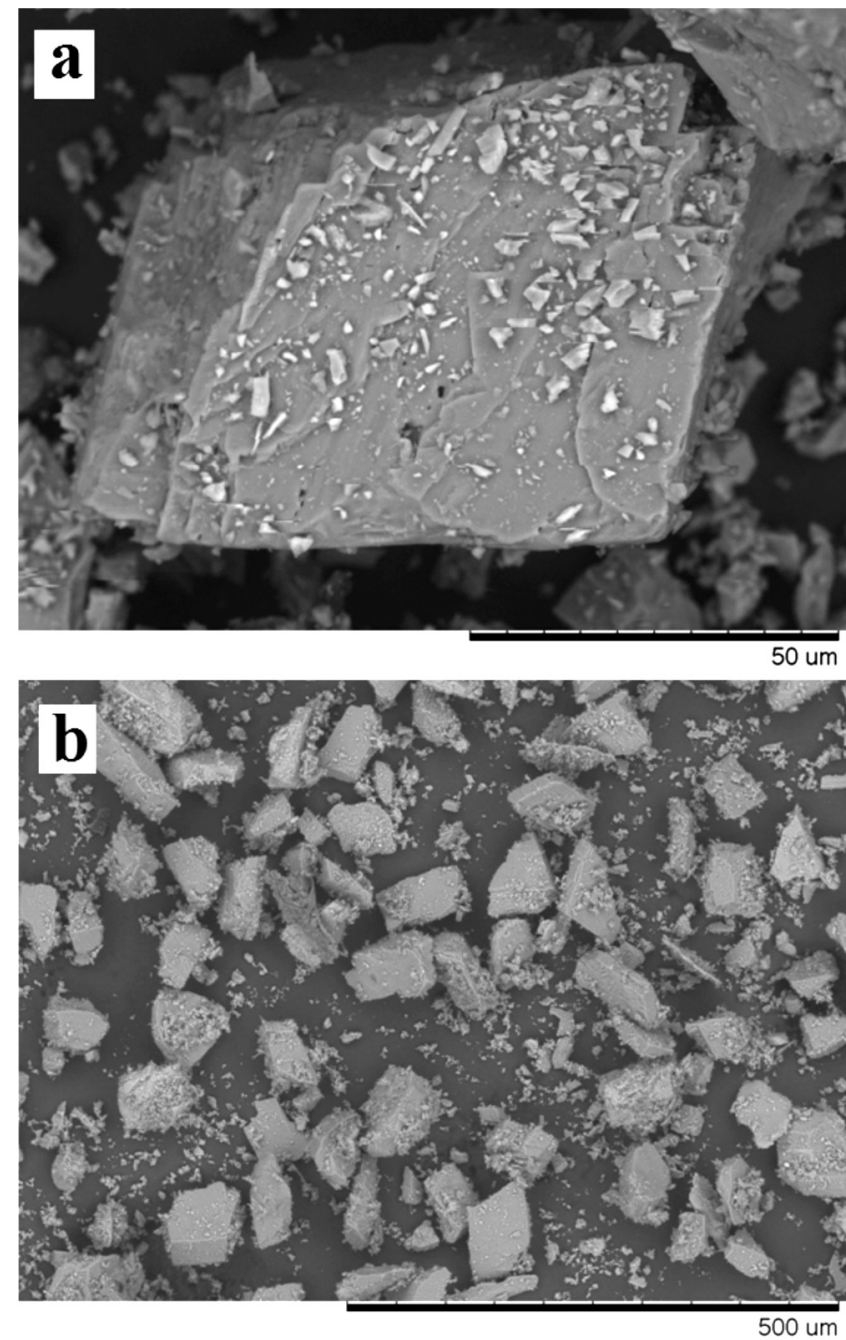

Figura 2: Micrografias obtidas em microscópio eletrônico de varredura do calcário dolomítico in natura. a) superfície compacta, b) distribuição de tamanho de partículas.

[Figure 2: SEM micrographs of in nature lime. a) compact surface, b) particle size distribution.]

Tabela II - Distribuição de tamanho de partículas e dados de textura para $\mathrm{D}$ in natura.

[Table II - Particle size distribution and texture data for D in nature.]

\begin{tabular}{cc}
\hline & $\begin{array}{c}\text { Granulometria } \\
\text { da amostra }(\mu \mathrm{m})\end{array}$ \\
\hline $\mathrm{D}_{10 \%}<$ & 3,81 \\
$\mathrm{D}_{50 \%}<$ & 54,07 \\
$\mathrm{D}_{90 \%}<$ & 83,42 \\
$\mathrm{D}_{\text {médio }}$ & 48,48 \\
Aesp $\left(\mathrm{m}^{2} / \mathrm{g}\right)$ & 4,9 \\
Volume de poros $\left(\mathrm{cm}^{3} / \mathrm{g}\right)$ & 0,0064 \\
Densidade $\left(\mathrm{g} / \mathrm{cm}^{3}\right)$ & 2,86 \\
\hline
\end{tabular}

Devido à estrutura e origem, a área específica medida e o volume de poros foram baixos, e são apresentados na Tabela II, juntamente com a distribuição de tamanho de 
partículas, medida por granulometria a laser. Como regra, as rochas calcárias têm baixa porosidade inicial [16]. A faixa de granulometria utilizada apresentou diâmetro médio de $\sim 50 \mu \mathrm{m}$, mas com algumas partículas $>100 \mu \mathrm{m}$. $\mathrm{O} \mathrm{D}_{10 \%}$ foi representado por partículas muito finas, menores que $3,81 \mu \mathrm{m}$.

\section{Caracterização do calcário calcinado}

A calcinação do calcário dolomítico em forno foi realizada a fim de analisar a textura e microestrutura desenvolvidas a $850{ }^{\circ} \mathrm{C}$ em ar, à pressão atmosférica. A calcinação provocou a redução de diâmetro médio e relativo das partículas, de acordo com fraturas apresentadas nas superfícies, e esta redução foi semelhante para calcinação por aquecimento gradual e por choque térmico. Na Fig. $3 \mathrm{~d}$ pode-se observar a maior quantidade de finos devido à fratura, quando comparado com o calcário in natura (Fig. 2 b). De acordo com os dados de distribuição de tamanho de partículas apresentado na Tabela III, verifica-se que na granulometria utilizada para o calcário dolomítico, a redução de diâmetro médio e relativo durante a calcinação a $850^{\circ} \mathrm{C}$ em forno não é tão expressiva, sendo a principal consequência da fratura de partículas o aumento de diâmetro da população de finos $\left(\mathrm{D}_{10 \%}\right)$. A área de reação para uma dolomita calcinada por choque térmico aumenta devido a fraturas na superfície, e pela fragmentação originada da decrepitação (para partículas maiores que $\sim 100 \mu \mathrm{m})$. Neste caso, os fragmentos menores facilitam

Tabela III - Distribuição de tamanho de partículas, textura e perda de massa para D calcinado.

[Table III - Particle size distribution, texture and weight loss for $D$ calcined.]

\begin{tabular}{ccc}
\hline $\begin{array}{c}\text { Granulometria da } \\
\text { amostra }(\mu \mathrm{m})\end{array}$ & $\begin{array}{c}\text { Aquecimento } \\
\text { gradual }\end{array}$ & $\begin{array}{c}\text { Choque } \\
\text { térmico }\end{array}$ \\
\hline $\mathrm{D}_{10 \%}<$ & 5,54 & 5,92 \\
$\mathrm{D}_{50 \%}<$ & 31,14 & 31,6 \\
$\mathrm{D}_{90 \%}<$ & 60,80 & 59,53 \\
$\mathrm{D}_{\text {médio }}$ & 32,80 & 32,84 \\
Aesp $\left(\mathrm{m}^{2} / \mathrm{g}\right)$ & 14,5 & 12,1 \\
Volume de poros $\left(\mathrm{cm}^{3} / \mathrm{g}\right)$ & 0,022 & - \\
Densidade $\left(\mathrm{g} / \mathrm{cm}^{3}\right)$ & 2,69 & - \\
Perda de massa $(\%)$ & 32,3 & 28,4 \\
\hline
\end{tabular}
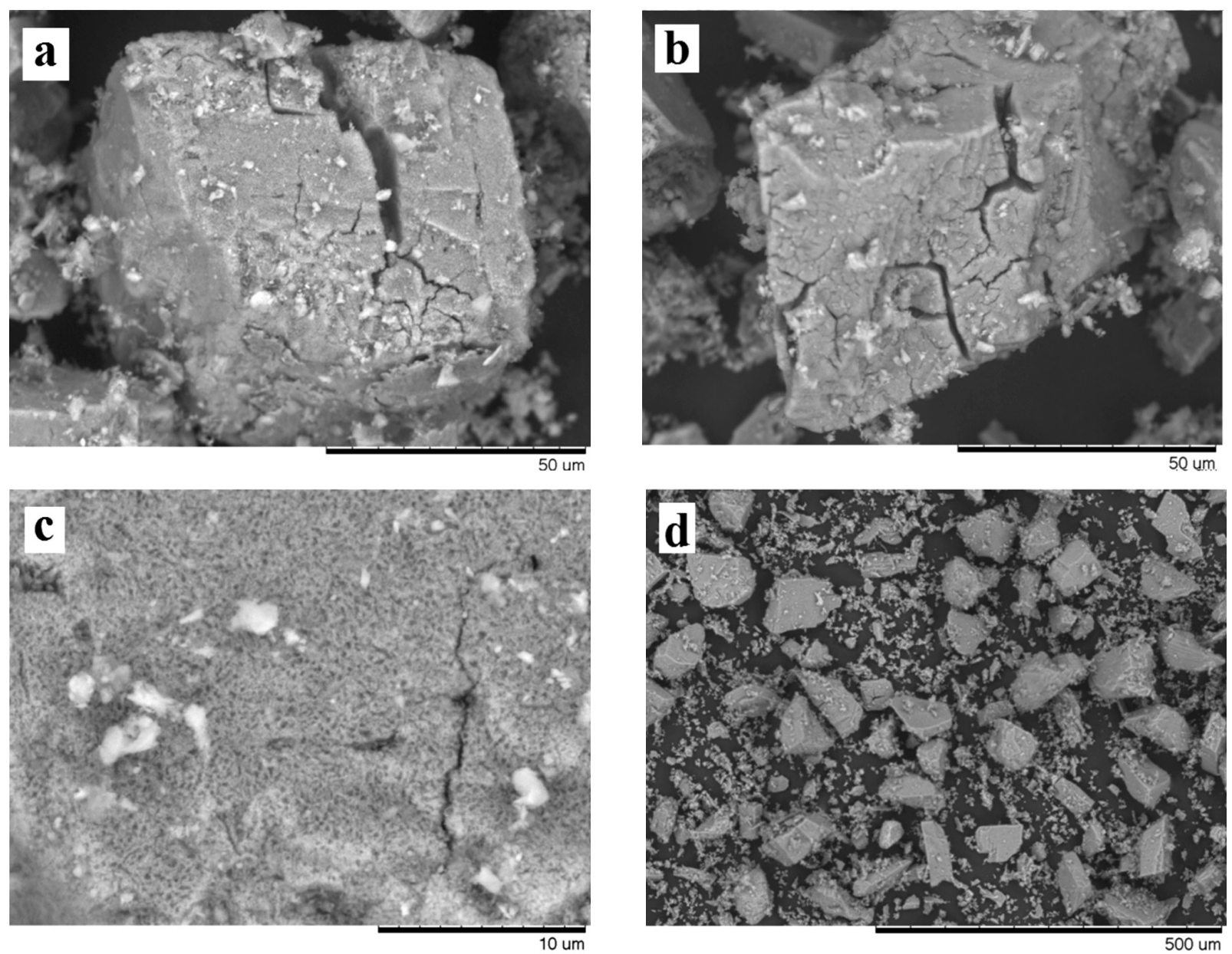

Figura 3: Micrografias obtidas em microscópio eletrônico de varredura do calcário dolomítico calcinado; a, c) calcário calcinado por aquecimento gradual e b) por choque térmico; d) granulometria após calcinação em forno.

[Figure 3: SEM micrographs of calcined lime; $a, c)$ gradual heating and b) thermal shock d) particle size after calcination on furnace.] 
o contato gás-sólido, diminuindo a resistência à difusão intrapartícula [17].

Durante a calcinação do calcário, as altas temperaturas e a difusão de $\mathrm{CO}_{2}$ mudam a textura e a microestrutura do $\mathrm{CaO}$ nascente, sendo marcado pela abertura de porosidade e micro e macrofraturas que eventualmente favorecem o completo rompimento de partículas maiores. As fraturas e, portanto, o aumento da população de finos, é importante no sentido de aumentar a área de superfície reativa da partícula. A Fig. 3 mostra a microestrutura da partícula calcária após a calcinação em forno. A microestrutura não variou com relação à calcinação por aquecimento gradual ou por choque térmico, e foi marcada por algumas fraturas e pequenos poros na superfície (Fig. 3).

A perda de massa por aquecimento gradual em forno foi de $32,3 \%$, similar à encontrada para calcinação em TG em atmosfera de $\mathrm{O}_{2}(36,7 \%)$, porém pouco menor. A curva TG/DTA para o calcário dolomítico é mostrada na Fig. 4. A diferença de perda de massa em TG é resultado da maior temperatura utilizada $\left(1200{ }^{\circ} \mathrm{C}\right)$ e ao maior controle da atmosfera de queima, ao contrário dos testes em forno $\left(850{ }^{\circ} \mathrm{C}\right)$. Em choque térmico a perda de massa foi menor $(28,4 \%)$, resultado do menor tempo de exposição à temperatura de queima $(\sim 30 \mathrm{~min})$ (Tabela III). Porém, mesmo não alcançando a calcinação completa, a microestrutura gerada e o grande aumento de área específica em forno por aquecimento gradual e por choque térmico tornam o calcário interessante com relação à superfície reativa. $\mathrm{O}$ aumento de área específica do calcário in natura para o calcinado de $4,9 \mathrm{~m}^{2} / \mathrm{g}$ para $14,49 \mathrm{~m}^{2} / \mathrm{g}$ é justificado pela porosidade encontrada na superfície e pelas micro e macrofraturas nas partículas. Além disso, a densidade medida para o calcinado também foi menor $\left(2,69 \mathrm{~g} / \mathrm{cm}^{3}\right)$ (Tabela III), justificado pela microestrutura gerada. O tipo de calcário e a temperatura de calcinação exercem forte influência sobre a área específica e a porosidade do calcinado [5]. Considerando que a calcinação em forno não foi completa, presume-se que a sinterização a $850{ }^{\circ} \mathrm{C}$ não tenha ocorrido, também de acordo com a alta área específica encontrada.

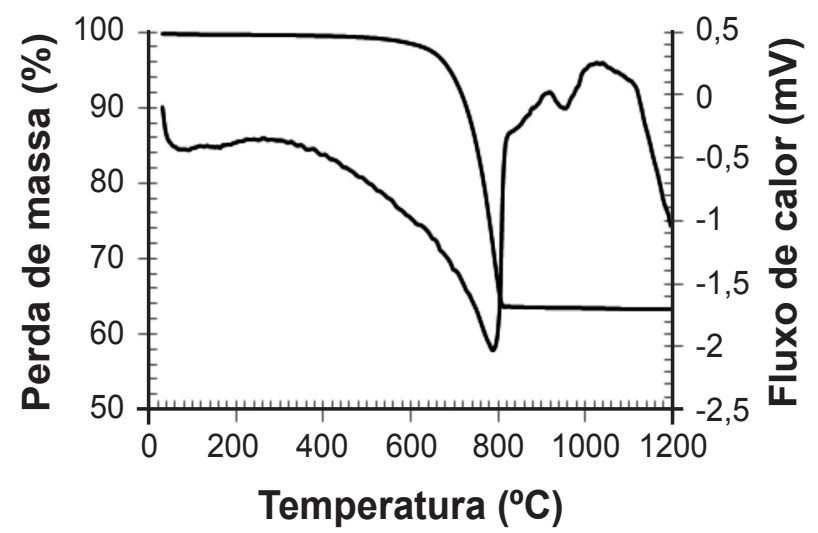

Figura 4: Curvas TG/DTA do calcário dolomítico calcinado em atmosfera de $\mathrm{O}_{2}$.

[Figure 4: TGA / DTA curvesr of dolomitic limestone calcined in $\mathrm{O}_{2}$ atmosphere.]

\section{Caracterização do calcário sulfatado}

A sulfatação do calcário foi em forno ao ar a $850{ }^{\circ} \mathrm{C}$ por $1 \mathrm{~h}$. O calcário calcinado foi acondicionado no forno entre os cadinhos contendo o carvão, para garantir que o $\mathrm{SO}_{2}$ pudesse entrar em contato com o sorvente. A formação de sulfato de cálcio $\left(\mathrm{CaSO}_{4}\right)$ em torno das partículas de calcário calcinado é comprovada por mapeamento por MEV/EDS, onde os pontos claros representam a presença de enxofre na amostra (Fig. 5 a, b). O ganho de massa de $17,95 \%$ com relação ao calcinado também sustenta a formação de sulfato de cálcio (Tabela IV).

Tabela IV - Distribuição de tamanho de partícula e textura para o calcário in natura, calcinado e sulfatado $(\mu \mathrm{m})$.

[Table IV - Distribution of particle size and texture to in nature, calcined and sulfated limestone $(\mu \mathrm{m})$.

\begin{tabular}{lccc}
\hline & $\mathrm{D}$ & $\mathrm{D}$ & $\mathrm{D}$ \\
& & calcinado & sulfatado \\
\hline $\mathrm{D}_{10 \%}<$ & 3,81 & 5,54 & 12,04 \\
$\mathrm{D}_{50 \%}<$ & 54,07 & 31,14 & 56,73 \\
$\mathrm{D}_{90 \%}<$ & 83,42 & 60,80 & 84,80 \\
$\mathrm{D}_{\text {médio }}$ & 48,48 & 32,80 & 53,79 \\
Aesp $\left(\mathrm{m}^{2} / \mathrm{g}\right)$ & 4,9 & 14,5 & 6,3 \\
Densidade $\left(\mathrm{g} / \mathrm{cm}^{3}\right)$ & 2,86 & 2,69 & 3,09 \\
Volume de poros $\left(\mathrm{cm}^{3} / \mathrm{g}\right)$ & 0,006 & 0,02 & 0,008 \\
Ganho de massa $(\%)$ & - & - & 17,95 \\
\hline
\end{tabular}

Com a sulfatação a distribuição de tamanho de partícula muda, Fig. 6. Com relação ao calcário in natura, a granulometria foi semelhante; porém, quando comparado com o sorvente calcinado a diferença na distribuição granulométrica fica mais evidente. Percebe-se a redução de diâmetro médio e relativo devido à calcinação, e em uma segunda etapa, durante a sulfatação do calcário calcinado ocorre o aumento do diâmetro médio e relativo (Tabela IV). O principal aumento notado no diâmetro foi com relação aos finos $\left(\mathrm{D}_{10 \%}\right)$, o que está de acordo com o fato de partículas menores apresentarem maior energia de superfície e, portanto, reagirem primeiro. A formação de uma camada de $\mathrm{CaSO}_{4}$ em torno das partículas de calcário podem influenciar no diâmetro medido das mesmas, além da agregação gerada durante a sulfatação.

A formação de sulfato reduz a área específica pelo rápido bloqueio dos poros [10]. Durante a sulfatação indireta, ocorre a formação de uma camada de sulfato não porosa, que dificulta a passagem dos gases mantendo o núcleo da partícula de $\mathrm{CaO}$ sem reagir. Foi verificada a redução de área específica e do volume de poros para o calcário sulfatado, além da densificação pela formação de uma camada em torno do mesmo (Tabela IV). Assim, a textura e microestrutura do sulfato de cálcio são muito diferentes da partícula de calcário calcinada.

As imagens obtidas em microscópio eletrônico de 

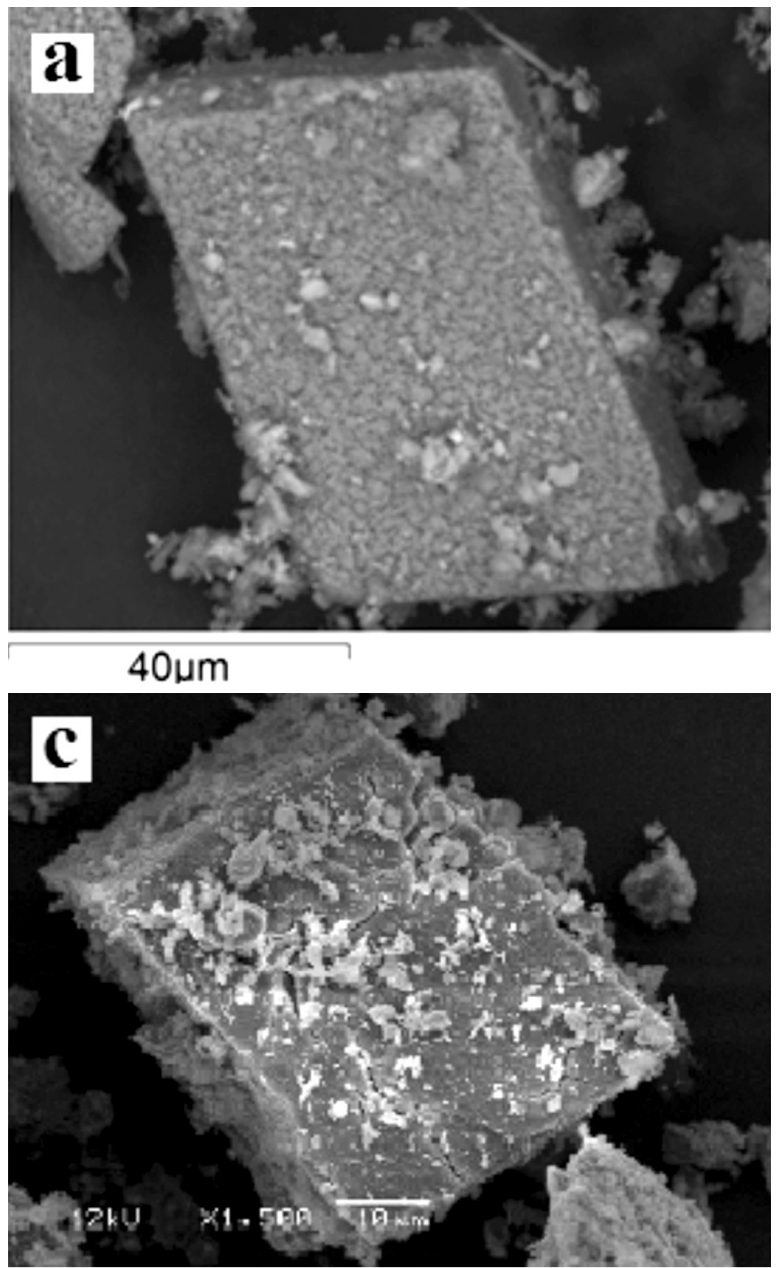

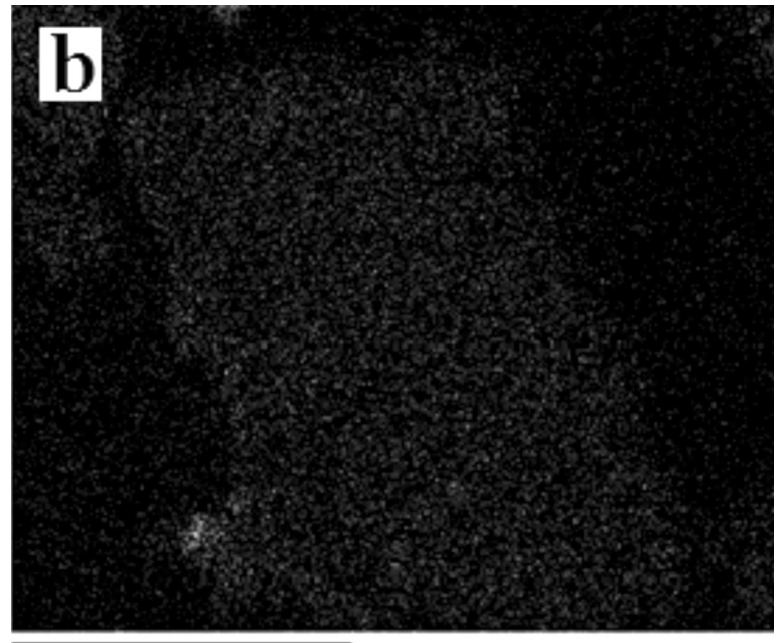

40um

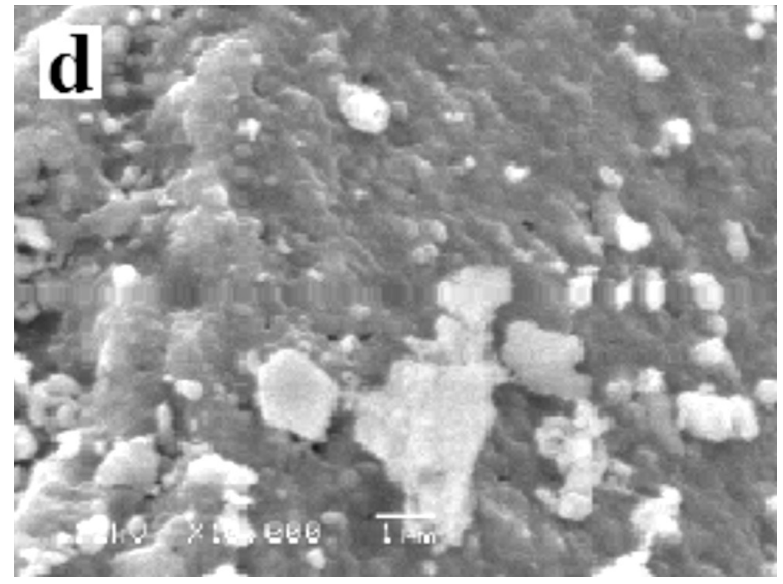

Figura 5: Micrografias obtidas em microscópio eletrônico de varredura do calcário sulfatado; a, b) mapeamento para enxofre por EDS na partícula; c) aspecto da partícula; d) superfície e porosidade após sulfatação.

[Figure 5: SEM micrographs of sulfated limestone; a, b) mapping for sulfur by EDS in the particle, c) aspect of the particle; d) after sulphation surface and porosity.]

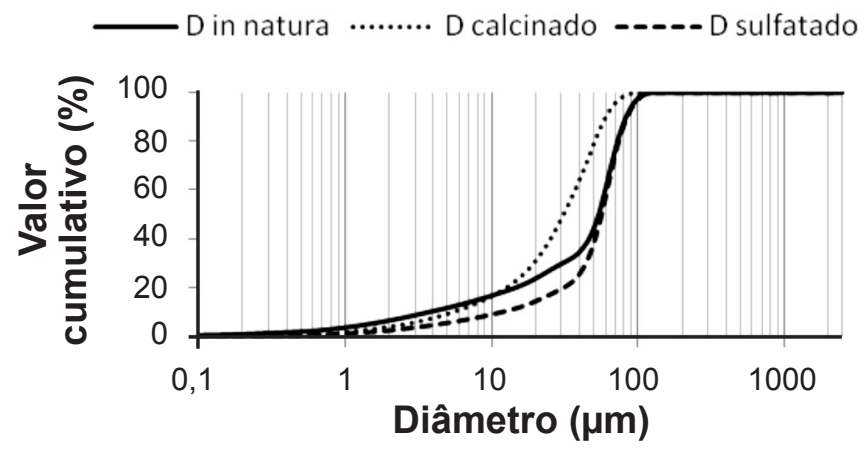

Figura 6: Distribuição granulométrica para o calcário dolomítico in natura, calcinado e sulfatado.

[Figure 6: Particle size distribution for in nature, calcined and sulfated limestone.]

varredura revelam uma fina camada uniforme na superfície que não chega a cobrir as fraturas maiores (Fig. 5c), e porosidade existente após a sulfatação (Fig. 5d). A porosidade após a sulfatação deve-se provavelmente à difusão em sentido inverso de $\mathrm{CO}_{2}$ do interior da partícula. Como o calcário dolomítico era compacto inicialmente, e já que não se alcançou a total calcinação devido às diferenças de perda de massa em TG e em forno, é possível que a parte mais interna do calcário ainda estivesse calcinando, gerando poros arredondados na camada de $\mathrm{CaSO}_{4}$.

\section{CONCLUSÕES}

O calcário dolomítico analisado in natura apresenta estrutura compacta, com baixa porosidade e área específica, conforme a caracterização em microscópio eletrônico de varredura. No entanto, as características iniciais da partícula, como a área de superfície específica e volume de poros aumentam drasticamente durante a calcinação. A microestrutura do calcinado revela uma significativa mudança na textura, apresentando grande quantidade de porosidade aberta na superfície das partículas, constituída por micro e macrofraturas. Face a isso, a densidade da partícula diminui. A ampla área reativa desenvolvida mostra que o calcário estudado apresenta bom potencial como sorvente a gases sulfurosos. As impurezas presentes não mostraram efeito na calcinação, como sinterização e 
fechamento da porosidade. Isto se deve ao fato delas não estarem associadas às partículas de dolomita, como é o caso do quartzo, principal impureza, o qual se apresenta muitas vezes como partícula individualizada em decorrência da moagem. A medição da granulometria mostra que a sulfatação leva ao aumento do diâmetro médio das partículas, provando que a mesma é um fenômeno de superfície externa. O mesmo pode-se concluir com a análise em microscópio eletrônico, na qual se observa o recobrimento da superfície externa das mesmas. O mapeamento por EDS mostra uma distribuição de enxofre em toda superfície das partículas sulfatadas analisadas.

A formação de uma camada de $\mathrm{CaSO}_{4}$ na superfície externa da partícula provoca redução na área específica e volume de poros da mesma, quando comparada à sua maior área específica originada durante a calcinação. No entanto, a calcinação a $850{ }^{\circ} \mathrm{C}$ por $1 \mathrm{~h}$ em forno faz com que o calcário dolomítico não calcine completamente, o que muda a microestrutura da partícula sulfatada pela presença de poros arredondados na camada de sulfato de cálcio, resultado da difusão do $\mathrm{CO}_{2}$ pela calcinação incompleta. Isto prova a importância do tamanho de partícula em relação à cinética da calcinação e dessulfuração, pois a parte interna da partícula pode ser elutriada do combustor sem reagir completamente.

\section{REFERÊNCIAS}

[1] J. S. Reed, "Principles of Ceramic Processing", $2^{a}$ Ed., Wiley Interscience (1995).

[2] A. B. da Luz, F. A. F. Lins. Freitas, Rochas \& minerais industriais: usos e especificações, Centro de Tecnologia Mineral, Rio de Janeiro, RJ (2005).

[3] P. M. Crnkovic, W. L. Polito, C. G. Silva Filho, F. E. Milioli, J. D. Pagliuso, Quím. Nova 27 (2004) 58.

[4] S. J. Gregg, K. S. W. Sing, "Adsorption, surface and porosity", 2a Ed., Academic Press (1982).

[5] A. M. Hayashi, Estudo do Efeito dos parâmetros físicos e químicos de adsorvente sólido no processo de adsorção de $\mathrm{SO}_{2}$ em calcário, Diss. Mestrado, UNICAMP, Campinas, SP (1996).
[6] S. C. Collar, Influência da estrutura de poros e do raio de grão na reatividade ao $\mathrm{SO}_{2}$ de calcinados de calcários gaúchos, Tese Dr., Universidade Federal do Rio Grande do Sul, RS (2001).

[7] Q. Zhong, I. Bjerle, Calcination kinetics of limestone and the microstructure of nascent $\mathrm{CaO}$, Thermochim. Acta 223 (1993) 109.

[8] E. R. R. Santana, Caracterização e reconstrução mineralógica de carvão, caulim, calcário e de cinzas sulfatadas geradas à temperatura de um leito fluidizado visando sua aplicação na indústria cimenteira, Tese Dr., Universidade Federal do Rio Grande do Sul, RS (2002).

[9] G. Hu, K. Dam-Johansen, S. Wedel, Oriented nucleation and growth of anhydrite during direct sulfation of limestone, Crystal Growth Design 8, 4 (2008) 1181.

[10] E. J. Anthony, D. L. Granatstein, Sulfation phenomena in fluidized bed combustion systems, Progress Energy Combustion Sci. 27 (2001) 215.

[11] K. Han, C. Lu, S. Cheng, G. Zhao, Y. Wang, J. Zhao, Effect of characteristics of calcium-based sorbents on the sulfation kinetics, Fuel 84 (2005) 1933.

[12] V. Manovic, E. J. Anthony, D. Loncarevic, $\mathrm{SO}_{2}$ Retention by $\mathrm{CaO}$-based sorbent spent in $\mathrm{CO}_{2}$ looping cycles, Ind. Eng. Chem. Res. 48 (2009) 6627.

[13] S. R. Bragança, Dessulfuração do gás de combustão do carvão candiota em leito fluidizado: influência da razão molar Ca/S, granulometria e composição química do sorbente, Diss. Mestrado, Universidade Federal do Rio Grande do Sul, RS (1996).

[14] G. Hu, K. Dam-Johansen, S. Wedel, J. P. Hansen, Review of the direct sulfation reaction of limestone, Progr. Energy Combustion Sci. 32 (2006) 386.

[15] W. Duo, K. Laursen, J. Lim, J. Grace, Crystallization and fracture: formation of product layers in sulfation of calcined limestone, Powder Technology 111 (2000) 154.

[16] F. Rubiera, A. B. Fuertes, J. J. Pis, V. Artos, G. Marbàn, Changes in textural properties of limestone and dolomite during calcinations, Termochim. Acta 179 (1991) 125.

[17] A. B. Fuertes, G. Velasco, T. Alvarez, M. J. Fernandez, Sulfation of dolomite particles at high $\mathrm{CO}_{2}$ partial pressures, Termochim. Acta 254 (1995) 63.

(Rec. 08/10/2012, Ac. 30/11/2012) 